\title{
Structural and kinematic analysis of a shutter from monocoque trailer
}

\author{
Lucreţia Popa ${ }^{1, *}$, Ştefan-Iulian Moise ${ }^{2}$, Victor Moise ${ }^{3}$, Vasilica Ştefan ${ }^{1}$ and Iulian Tabără ${ }^{3}$ \\ ${ }^{1}$ INMA Bucharest, 6 Ion Ionescu de la Brad, Bucharest, Romania \\ ${ }^{2}$ Etudes et Productions Schlumberger, Paris, France \\ ${ }^{3}$ POLITEHNICA University of Bucharest, Romania
}

\begin{abstract}
The bodies of trucks or trailers are provided with automatic folding shutters to ease the discharge of the transported materials. Typically, these shutters are powered by mechanisms that have active motor groups such as RRTaR or RR-RR-RTaR (i.e. motor dice or triads) and passive motor groups such as RRR, RR-RR-RR etc. If the technological forces are high and the relative speeds between the elements forming the steering coupler are small, the motor groups are formed by rigid bars and hydraulic cylinders. If relatively high gear ratios are required, then pneumatic cylinders may be used. If required relatively high speeds in the driving couplings, then you can use pneumatic cylinders. This paper presents structural and kinematic analysis of a shutter from a trailer used to transport bulk agricultural products, discharge towards the back. For the kinematic analysis of the folding shutter mechanism, computational procedures written in the Matlab syntax are used. The results of the calculations are presented in tabular and diagrams. After the cinematic analysis of the mechanism, it is possible to perform its cinetostatic analysis, i.e. the determination of the reactions from the kinematic couplers, as well as the hydraulic force in the hydraulic cylinder. Results can be used for the dimensional verification of the chosen elements.
\end{abstract}

\section{Introduction}

Trailers for the transport of bulk agricultural products may have different forms of construction, in terms of the way of unloading the cargo.

They can download the products tipping on the side, right, left or on both sides, but there are constructive variants where the unloading is done backwards.

The trailers, which are built in the monocoque construction, perform only the rear discharge and are fitted with a shutter by manual opening, but the newer trailers are equipped with automatic opening shutters.

The automatic shutter of the trailer provides operator comfort, who is no longer required to descend from the tractor to open the shutter, return to the tractor to command the

\footnotetext{
* Corresponding author: Lucreţia Popa, lucretia popa@yahoo.com
} 
unloading and then lower down the shutter after unloading the cargo, after returning the body trailer to the travel position.

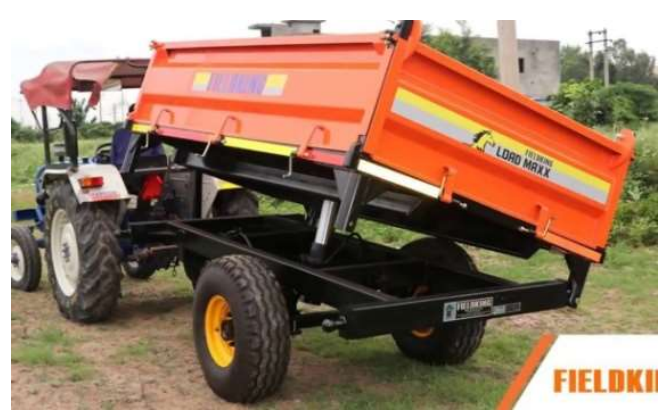

Fig. 1. Two sides tipping trailer.

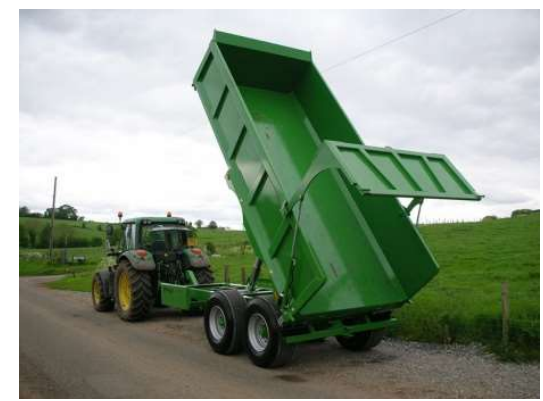

Fig. 2. Monocoque trailer by automatique shutter.

Making a mechanical model that includes structural and kinematic analysis of a shutter fitted to the monocoque trailer is important in terms of construction and functioning.

The kinematic analysis of the mobile shutter drive mechanism gave useful information on the positions, speeds and the accelerations of the mechanism elements, without taking into account the forces acting on them.

In this paper, structural and kinematic analysis of the mechanism that perform the opening of the mobile shutter will be presented.

\section{Material and method}

In order to determine the kinematic parameters of the elements of the mechanism, it is necessary to know the structural groups in its composition, the dimensions of the elements, the initial position of the mechanism, as well as the kinematic parameters in the motor coupling. Figure 3 shows the schematic kinematic mechanism for tilting the shutter of trailer SR8, design to INMA Bucharest. The mechanism is surprised in any position.

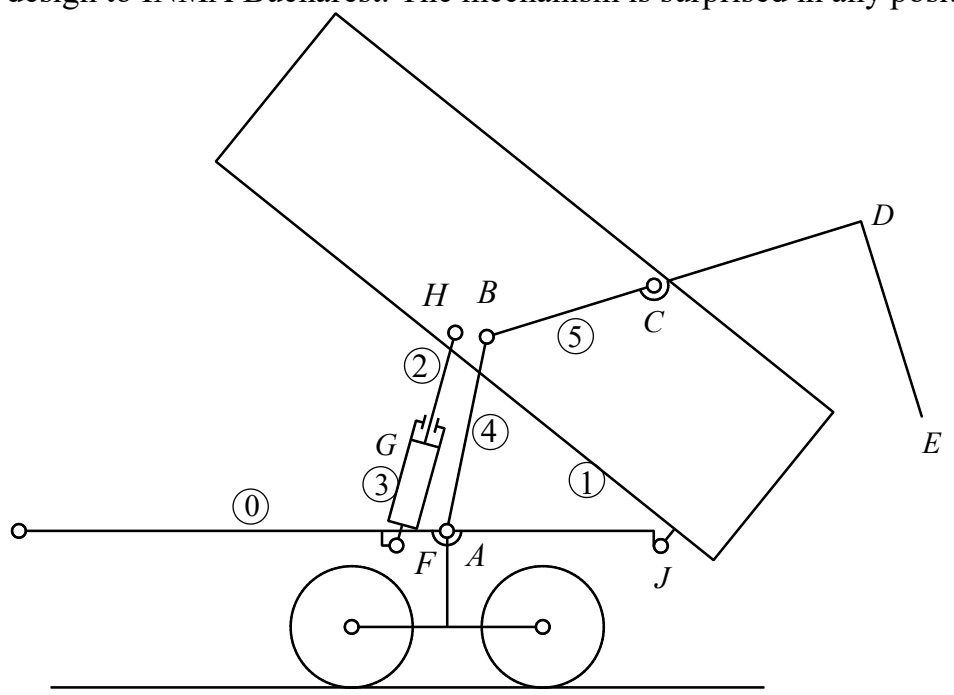

Fig. 3. The kinematic scheme of the mechanism for acting the trailer shutter. 


\subsection{Structural analysis of the mechanism}

The structural analysis of the mechanism consists in establishing kinematic couplers, determining the mobile elements, establishing the degree of mobility, drawing up the structural scheme, establishing the structural structures of the mechanism, constructing the multipolar scheme and establishing the structural relationship.

Observing the relative movements between the elements of the mechanism, it is found that it has the following inferior couplings: $A(0 R 4), B(4 R 5), C(1 R 5), F(3 R 0), G(2 T 3)$, $H(1 R 2)$ and $J(1 R 0)$.

The number of superior couplings is zero.

The mobile elements of the movement are: $1(C, H, J), 2(G, H), 3(F, G), \quad 4(A, B)$, and $5(B, C)$.

Taking into account the number of moving elements and the number of kinematic couplings, the degree of mobility of the mechanism results [1-6], namely $M=1$, meaning only one independently parameter is required so that the elements of the mechanism having unique determined movements.

Figure 4 shows the structural diagram of the climbing mechanism of the shutter, and Figure 5 presents the multipolar scheme and its structural relationship.

Figure 5 shows that the mechanism consists of $Z 0$ base, motor dyad $\operatorname{RRTaR}(1,2,3)$, and passive dyad $R R R(4,5)$.

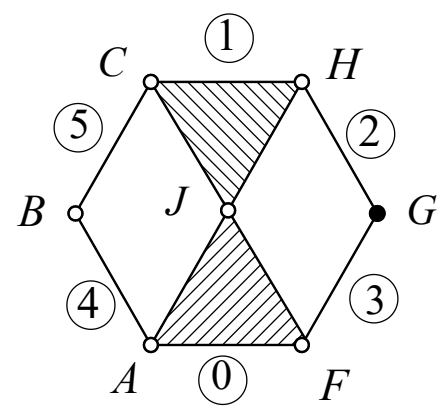

Fig. 4. Structural scheme of the mechanism.

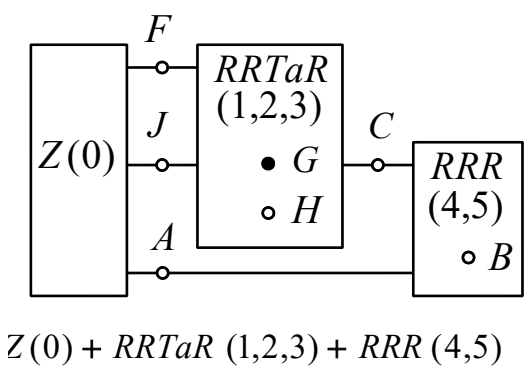

Fig. 5. Multipolar scheme of the mechanism and structural relationship.

\subsection{Kinematic analysis of the mechanism}

Figure 6 shows the kinematic diagram of the mechanism, with the position parameters being highlighted. 


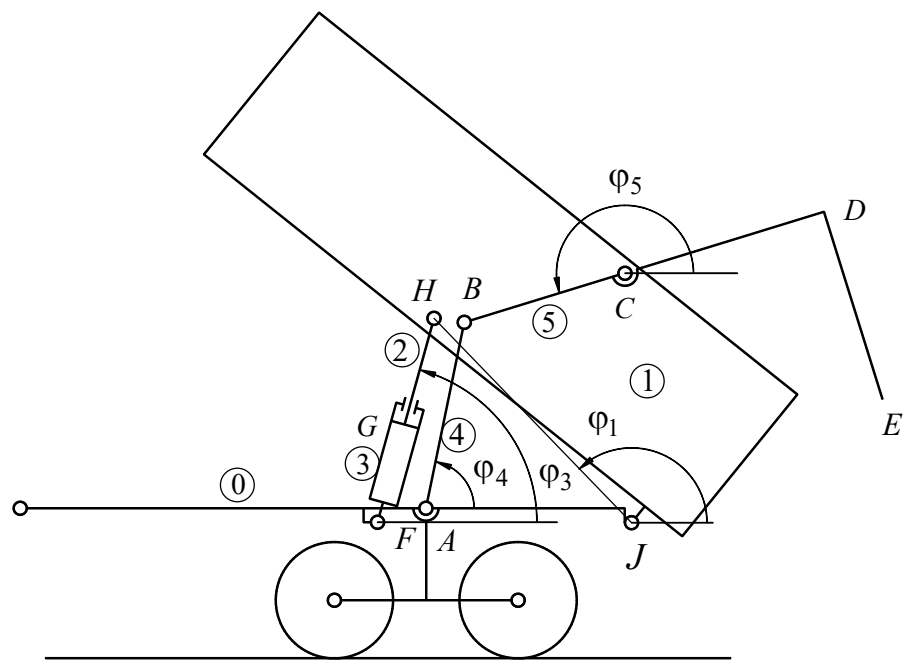

Fig. 6. The kinematic scheme of the mechanism, with highlighting position of parameters.

For the kinematic analysis of the mechanism are used calculation procedures written by the authors in the Matlab syntax.

The theoretical study was applied using the constructive parameters of a trailer equipped with automatic shutter, designed to INMA Bucharest, namely SR-8, showed in Figure 7 [7].

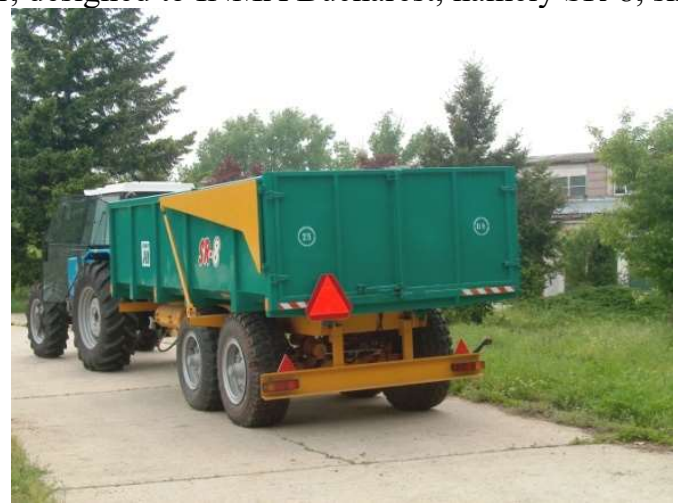

Fig. 7. Trailer with payload capacity of 8 tons on transport position.

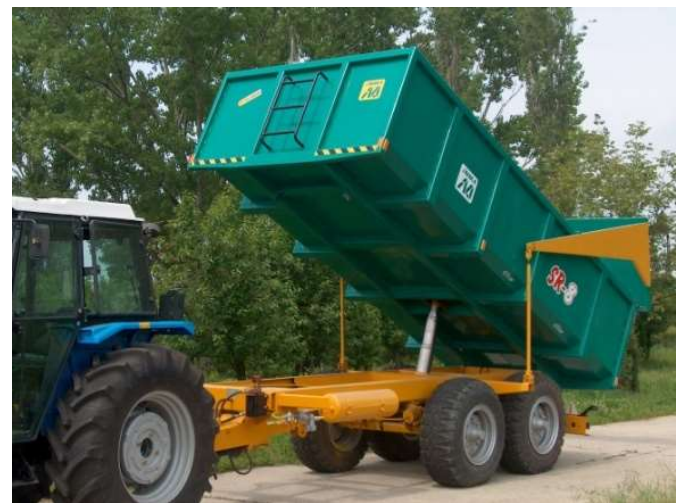

Fig. 8. Trailer with payload capacity of 8 tons on tipping position. 
For the kinematic analysis of the mechanism, the following numerical data were used (fig.6): $A B=1.270 \mathrm{~m}, B C=1.000 \mathrm{~m}, C J=1.580 \mathrm{~m}, F H_{\text {initial }}=0.216 \mathrm{~m}, H J=1.520$ $\mathrm{m}$, Piston stroke $=1.150 \mathrm{~m}, X A=0.000 \mathrm{~m}, \quad Y A=0.000 \mathrm{~m}, \quad X F=-0.200 \mathrm{~m}$, $Y F=-0.185 \mathrm{~m}, \quad X J=1.340 \mathrm{~m}, \quad Y J=-0.050 \mathrm{~m}, \quad \angle(\overline{J C}, \overline{J B})=0.769838 \mathrm{rad}$, Lifting time $=20 \mathrm{sec}$.

Transmission function in the hydraulic cylinder: lrsin (sinusoidal acceleration - zero acceleration - sinusoidal acceleration).

The numeric values of the angles done by vectors $\overline{J H}, \overline{F H}, \overline{A B}$ and $\overline{C B}$ with the positive sens of axis $O X$ are presented In Table 1.

Table 1. The numeric values of the angles done by vectors $\overline{J H}, \overline{F H}, \overline{A B}$ and $\overline{C B}$ with the positive sens of axis $O X$.

\begin{tabular}{|c|c|c|c|c|}
\hline Position & fi 1 & fi 2 & fi 4 & f 5 \\
\hline $\mathbf{0}$ & 3.0884 & 1.4685 & 2.1850 & 3.2122 \\
\hline $\mathbf{1}$ & 3.0882 & 1.4686 & 2.1848 & 3.2123 \\
\hline $\mathbf{2}$ & 3.0871 & 1.4689 & 2.1836 & 3.2125 \\
\hline $\mathbf{3}$ & 3.0843 & 1.4698 & 2.1804 & 3.2132 \\
\hline $\mathbf{4}$ & 3.0792 & 1.4712 & 2.1745 & 3.2145 \\
\hline $\mathbf{5}$ & 3.0712 & 1.4729 & 2.1655 & 3.2165 \\
\hline $\mathbf{6}$ & 3.0602 & 1.4743 & 2.1530 & 3.2192 \\
\hline $\mathbf{7}$ & 3.0465 & 1.4749 & 2.1374 & 3.2226 \\
\hline $\mathbf{8}$ & 3.0304 & 1.4743 & 2.1190 & 3.2266 \\
\hline $\mathbf{9}$ & 3.0125 & 1.4724 & 2.0985 & 3.2310 \\
\hline $\mathbf{1 0}$ & 2.9938 & 1.4692 & 2.0769 & 3.2358 \\
\hline$\ldots \ldots \ldots \ldots \ldots \ldots \ldots \ldots \ldots \ldots \ldots \ldots \ldots \ldots \ldots \ldots \ldots \ldots \ldots \ldots \ldots \ldots \ldots \ldots \ldots \ldots \ldots \ldots \ldots \ldots \ldots \ldots \ldots$ & $3 \ldots \ldots \ldots \ldots \ldots \ldots$ \\
\hline $\mathbf{4 0}$ & 2.4084 & 1.2285 & 1.3526 & 3.4322 \\
\hline $\mathbf{4 1}$ & 2.3880 & 1.2188 & 1.3241 & 3.4428 \\
\hline $\mathbf{4 2}$ & 2.3686 & 1.2096 & 1.2965 & 3.4535 \\
\hline $\mathbf{4 2}$ & 2.3510 & 1.2012 & 1.2710 & 3.4637 \\
\hline $\mathbf{4 4}$ & 2.3359 & 1.1940 & 1.2489 & 3.4728 \\
\hline $\mathbf{4 5}$ & 2.3239 & 1.1883 & 1.2309 & 3.4805 \\
\hline $\mathbf{4 6}$ & 2.3151 & 1.1841 & 1.2177 & 3.4862 \\
\hline $\mathbf{4 7}$ & 2.3093 & 1.1813 & 1.2090 & 3.4901 \\
\hline $\mathbf{4 8}$ & 2.3062 & 1.1798 & 1.2042 & 3.4922 \\
\hline $\mathbf{4 9}$ & 2.3051 & 1.1793 & 1.2024 & 3.4930 \\
\hline $\mathbf{5 0}$ & 2.3049 & 1.1792 & 1.2022 & 3.4931 \\
\hline \multicolumn{4}{|r|}{} \\
\hline
\end{tabular}

Figure 9 shows the variation diagrams of the angles done by vectors $\overline{J H}, \overline{F H}, \overline{A B}$ and $\overline{C B}$ with the positive sens of axis $O X$.

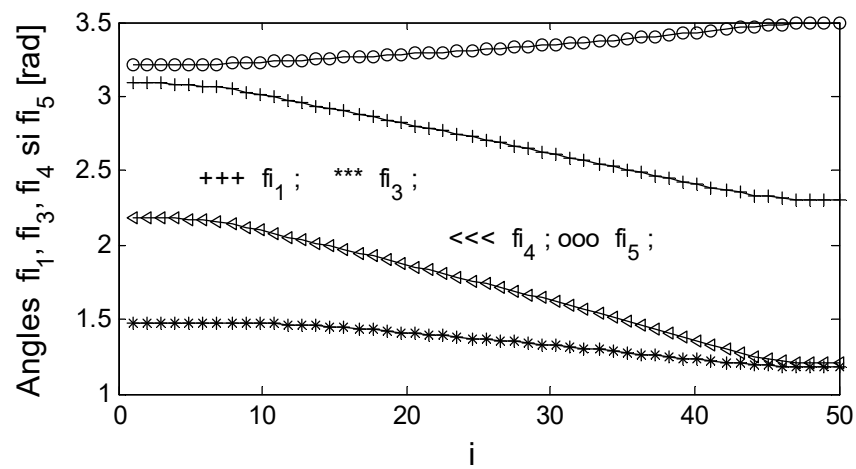

Fig. 9. Variation diagrams of the angles done by vectors $\overline{J H}, \overline{F H}, \overline{A B}$ and $\overline{C B}$ with the positive sens of axis $O X$. 
Figures 10 and 11 show variation diagrams of velocity and angular acceleration of the moving parts.

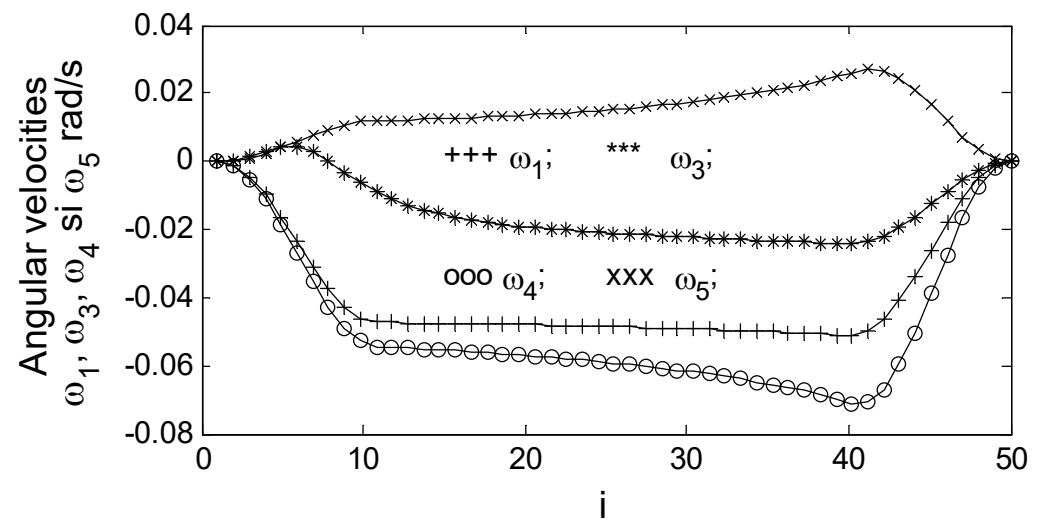

Fig. 10. Angular velocity variation diagrams of mobile elements.

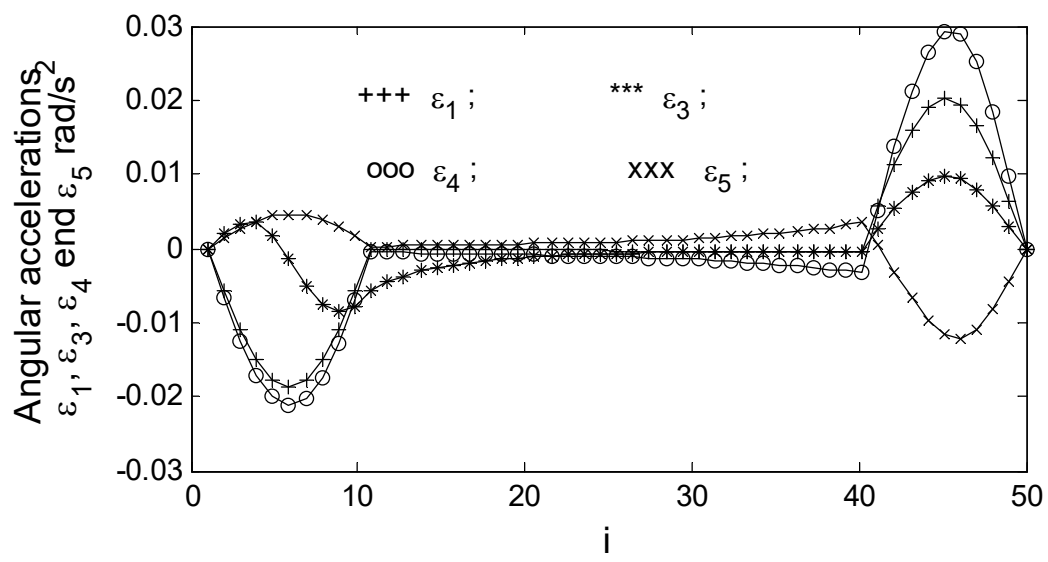

Fig. 11. Angular acceleration variation diagrams of mobile elements.

\section{Conclusions}

The kinematic analysis of the mechanism provides useful information regarding the tipping speed of the trailer body and, implicitly, the cargo. A high-speed causes damage to the automatic shutter, and a small one causes a long discharging time.

The kinematic analysis made by the simulation enables the proper dimensioning of the elements of the mechanism, so that in the key positions the shutter is at the level that provide the discharge section.

The kinematic analysis realized in this paper is useful for the dynamic analyse, which will be perform in another research.

\section{Acknowledgement}

This work was supported by a grant of the Romanian Research and Innovation Ministry, through Programme 1 - Development of the National Research-Development System, subprogramme 1.2 - Institutional performance - Projects for financing excellence in RDI, contract no. 16PFE. 


\section{References}

1. I.I. Artobolevski, Théorie des Mécanismes et des Machines (Theory of Mechanisms and Machines). (Ed. Mir, 1977)

2. C. Duca, Fl. Buium et al. Mechanisms, (Gh. Asachi Publishing House, 2003).

3. V. Moise, E. Maican, Şt. I. Moise, Numerical methods in engineering (Bren Publishing House, 2003)

4. V. Moise, I. Simionescu, M. Ene et al. Analysis of Applied Mechanisms, (Printech Publishing House, 2008)

5. Chr. Pelecudi. The precision of the mechanisms, (Publishing House of the Academy of RSR, 1975)

6. I. Simionescu, V. Moise, Mechanisms, (Technical Publishing House, 1999)

7. https://www.inma.ro/Prez_CDI/SR_8.pdf 